\title{
Serotonin GPCR-based biosensing modalities in yeast
}

Bettina Lengger ${ }^{1}$, Emma E. Hoch-Schneider ${ }^{1}$, Christina N. Jensen ${ }^{1}$, Tadas Jakočiūnas ${ }^{1}$, Emil D. Jensen ${ }^{1}$, and Michael K. Jensen ${ }^{1 *}$

${ }^{1}$ Novo Nordisk Foundation Center for Biosustainability, Technical University of Denmark, Kgs. Lyngby, Denmark

* To whom correspondence should be addressed. Michael K. Jensen, email: mije@biosustain.dtu.dk

\section{Highlights}

- Human serotonin G protein-coupled receptors display promiscuous Ga coupling in yeast

- Ga-coupled serotonin receptors display up to 64-fold changes in reporter expression output

- Differences in Ga protein evokes 25- and 2-fold difference in $\mathrm{EC}_{50}$ and sensitivity, respectively

- Serotonin receptor 5-HT4 and human SNP variants display physiologically relevant $\mathrm{EC}_{50}$ values in yeast

- 5-HT4 can be applied for high-resolution biosensing of serotonin produced from yeast

\section{Summary}

Serotonin is a key neurotransmitter involved in numerous physiological processes and serves as an important precursor for manufacturing bioactive indoleamines and alkaloids used in the treatment of human pathologies. In humans, serotonin sensing and signaling can occur by $12 \mathrm{G}$ protein-coupled receptors (GPCRs) coupled to G proteins. To 
systematically assess serotonin GPCR signaling, we characterized reporter gene expression of a 144-sized library encoding all 12 human serotonin GPCRs in combination with 12 different Ga proteins in yeast exposed to serotonin. For the 5-HT4 receptor, we observe 25and 64-fold changes in $\mathrm{EC}_{50}$ values and dynamic reporter gene outputs, respectively. Furthermore, we show that optimal biosensing designs enable high-resolution sensing of serotonin produced in yeast, as well as provide a platform for characterization of 19 serotonin GPCR polymorphisms found in human populations. Taken together, our study highlights serotonin biosensing modalities of relevance to both biotechnological and human health applications.

\section{Keywords}

GPCR, serotonin, 5-HT receptor, polymorphism, biosensor, yeast

\section{Introduction}

Serotonin is a monoamine neurotransmitter largely confined to the digestive and central nervous systems of humans, and implicated in a plethora of biological functions in humans, including mood, feelings, eating, and sleeping (Berger et al., 2009). In humans a total of 13 serotonin receptor genes and 1 pseudogene are found, and encodes for a total of 12 serotonin G protein-coupled receptors (GPCRs) and 1 ionotropic channel, together mediating serotonin signaling (Nichols and Nichols, 2008). Collectively, GPCRs are seventransmembrane proteins, which allow cells to respond to extracellular stimuli by coupling the binding of a ligand to the activation of intracellular signaling pathways (Zhang et al., 2015). The intracellular signaling through GPCRs is mediated via a ligand-mediated conformational change serving as a guanine-exchange factor to activate heterotrimeric guanine nucleotidebinding protein (G protein), consisting of the three subunits $G a, G \beta$ and $G \square$ (Syrovatkina et al., 2016). Binding of a ligand to the GPCR promotes a conformational change in the receptor, which in turn activates the GPCR-bound $G$ a subunit of the $G$ protein. The exchange of Ga- bound GTP to GDP promotes the dissociation of the G protein from the GPCR as well as the separation of the Ga subunit from the Gß $\square$ dimer (Leberer et al., 1992). Following dissociation, the subunits relay intracellular signalling to ultimately effectuate an adequate transcriptional reprogramming in response to the extracellular milieu (Marinissen and Gutkind, 2001). While these modules constitute the core GPCR signalling, a dearth of knowledge challenges our understanding of how the approx. 800 GPCRs encoded in the human genome couple through 16 different Ga subunits (Pándy-Szekeres et al., 
2018), notwithstanding the structure-affinity relationship between the great diversity of ligands and the GPCRs which have evolved to respond to them, including light, hormones, and small molecules, like serotonin ((Lengger and Jensen, 2020; UniProt Consortium, 2021)).

For more than three decades yeast has served as a platform for studying human GPCRs (Brown et al., 2000; King et al., 1990) with great potential in both medical and biotechnological application areas (Lengger and Jensen, 2020). The vast majority of GPCR studies in yeast are based on the mating pathway naturally activated by pheromone through the yeast mating-factor GPCRs Ste2/3 (Versele et al., 2001). Upon ligand activation, successful coupling of a heterologous GPCR with the yeast mating pathway can occur through coupling to the yeast Ga protein GPA1, which subsequently activates the mitogenactivated protein (MAP) kinase cascade consisting of Ste5/Ste7/Ste11, ultimately resulting in the activation of 100 s of pheromone responsive genes (Lengger and Jensen, 2020). While a few studies successfully proved coupling of human GPCRs to GPA1 (Ehrenworth et al., 2017; King et al., 1990; Mukherjee et al., 2015), a key contribution to potentiate coupling of heterologous GPCRs to the yeast mating pathway was the discovery of improved coupling when exchanging the C-terminal five amino acids in the G $\square$ part of GPA1 with complementary 5-mer human $\mathrm{G} \square$ signatures, also referred to as chimeric Ga proteins (Brown et al., 2000; Conklin and Bourne, 1993; Nakamura et al., 2015; Shaw et al., 2019). Likewise, knockout of SST2, a negative regulator of GPA1, and FAR1, an inducer of cell cycle arrest during mating, have been key steps to increase heterologous GPCR signalling in yeast, as demonstrated previously (Dohlman et al., 1996; Price et al., 1995), ultimately enabling the development of whole-cell biosensors based on >50 GPCRs (Kapolka et al., 2020; Lengger and Jensen, 2020; Shaw et al., 2019).

For serotonin GPCRs, three out of the twelve human serotonin GPCRs have successfully coupled to the yeast mating pathway, namely 5-HT1A (Brown et al., 2000), 5HT1D (Brown et al., 2000; Nakamura et al., 2015) and the 5-HT4 receptors (Bean et al., 2021; Ehrenworth et al., 2017; Kapolka et al., 2020; Shaw et al., 2019). Likewise, in yeast, 10 mutants of the $5-\mathrm{HT} 1 \mathrm{~A}$ receptor have been engineered to elucidate polymorphisms impacting receptor activation (Nakamura et al., 2015), while Kapolka et al. recently reported coupling of 5-HT4 with all 10 chimeric Ga proteins variants (Kapolka et al., 2020). Importantly, while yeast only provides a minimal platform for studying heterologous GPCR signalling through its mating pathway, physiologically relevant pharmacological properties as well as receptor specificity for the Ga chimera have shown to be consistent with $\mathrm{EC}_{50}$ values and cognate mammalian Ga protein coupling, respectively (Brown et al., 2000; Nakamura et al., 2015). Likewise, for biotechnological purposes, microbial production in yeast of a range of GPCR agonists with clinical applications can offer a solution for supply chain stability and 
scalability of production (Galanie et al., 2015; Luo et al., 2019). However, optimizing heterologous biosynthetic pathways for human bioactives in yeast using metabolic engineering is often a tedious endeavor, involving complex engineering to create optimal pathway designs for fermentation-based manufacturing of such bioactives. Here, GPCRbased serotonin biosensors have shown promising results with a 5-HT1A-based sensor coupled to the GPA1/Gai3 chimera resulting in a sensor with $300 \%$ increase over basal fluorescence after activation with serotonin (Nakamura et al., 2015). Using a 5-HT4 based sensor, Ehrenworth et al. recently demonstrated that yeast-produced serotonin could be detected with a 2 -fold change (Ehrenworth et al., 2017). Still, while serotonin receptors have been characterized in yeast, no systematic approach has been performed to study Ga protein coupling of all human serotonin receptors, and the use of current best-performing serotonin GPCRs for biotechnological purposes suffers from low dynamic output ranges (Ehrenworth et al., 2017).

In this paper, we describe the systematic characterization of human serotonin GPCRmediated biosensing modalities in yeast. Specifically, we characterize signalling in 144 different engineered yeast strains expressing all 12 human serotonin receptors in combination with 12 different $\mathrm{Ga}$ protein designs, and furthermore present the characterization of 19 serotonin GPCR polymorphisms mined from the 1,000 Genome Project (1000 Genomes Project Consortium et al., 2015; Spooner et al., 2018). From this, we report serotonin and prucalopride dose-response curves for a total of $>30$ biosensing designs and apply an optimized biosensing design for high-resolution screening of a yeast strain library engineered to produce serotonin. Collectively, these results provide a resource on chimeric Ga coupling of the human serotonin GPCRs.

\section{Results}

\section{Yeast Ga library screen reveals signalling from activated human serotonin receptors}

In order to systematically investigate the potential to couple any of the 12 human serotonin receptors to the yeast mating pathway, we first mined the Human Protein Atlas database (Uhlén et al., 2015) for tissue- and organ-specific expression patterns of genes encoding the receptors in search of physiological parameters which could be leveraged to confer signalling from these human receptors in a yeast cell.

First, as several of the genes of interest produced splice variants, we selected the corresponding Ensembl transcript IDs (Supplementary Table S1) by amino acid similarity to the UniProt canonical sequence. From this analysis it is evident that for each of the serotonin GPCRs maximum expression occurs in different tissues (Figure 1A). The 5-HT6, 5-HT2C, 
5-HT2A and 5-HT5A receptors express most abundantly in the cerebral cortex, just as 5HT7 expression is maximal in the parathyroid gland. In female reproductive tissues, 5-HT1B and 5-HT1F express in high levels in the placenta, 5-HT1A and 5-HT1E in the ovaries, and $5-\mathrm{HT} 2 \mathrm{~B}$ express in the endometrium and cervix most abundantly. In the gastrointestinal tract, 5-HT1D is most abundantly expressed in the small intestine and duodenum. Similarly, 5-HT4 shows high expression in the small intestine, but comparably lower levels in the rectum, colon, and duodenum. Previously, 5-HT4 has been identified to be highly expressed in the gastrointestinal tract and is a target for drugs for gastrointestinal disorders (Manabe et al., 2010; Wong et al., 2010). Taken together, the 5-HT class of receptors are expressed at different abundances and tissues.

Next, we performed a combinatorial library screen founded on 12 different Ga protein background strains expressing either a yeast-native GPA1 Ga protein, one of $10 \mathrm{GPA} 1 / \mathrm{Ga}$ chimeras, or a truncated GPA1 (tGPA1) serving as a negative control (Brown et al., 2000; Shaw et al., 2019). Based on this platform, we transformed plasmids containing one of each of the 12 human serotonin GPCRs into the 12 different Ga background strains creating a library of 144 serotonin GPCR:Ga strains. In this setup, successful coupling of a human serotonin GPCRs with the yeast mating pathway will result in the activation of a synthetic transcription factor, which binds to a synthetic promoter to induce expression of sfGFP in the presence of serotonin (Figure 1B). As several serotonin GPCRs are highly expressed in both gastrointestinal tissues with lowered $\mathrm{pH}$ as well as in the brain (Figure 1A), we hypothesized that $\mathrm{pH}$ could play a role in receptor expression and/or coupling, and thus we screened the GPCR:Ga library at both $\mathrm{pH} 4.8$ and 7.2 spanning a physiological relevant $\mathrm{pH}$ range for both human serum and yeast cultivation medium (Figure 1C). At both pHs we cultivated the library in the absence of serotonin and in the presence of $100 \mu \mathrm{M}$ serotonin and scored relative GFP reporter read-outs following $4 \mathrm{hrs}$ of induction.

From this screen, we found strains expressing $5-\mathrm{HT} 4$ to be activated by serotonin, at both $\mathrm{pH} 4.8$ and 7.2, and in all Ga backgrounds excluding the truncated Ga control (tGPA1) (Figure 1C). Fold-inductions for the 5-HT4 receptor at $\mathrm{pH} 4.8$ ranged between 1.8-fold for Gas/olf coupling and 64-fold for Gaz coupling, followed by 48-fold Gai3 and 46-fold for yeast-native GPA1. Interestingly, looking at the three highest-induced Ga backgrounds for 5HT4 at pH 4.8; Gaz, Gai3 and GPA1, they showed reduced fold-inductions of 4, 17 and 13, respectively when using media at $\mathrm{pH} 7.2$ (Figure 1C). In contrast, low-induced 5-HT4:Ga background strains tested at $\mathrm{pH} 4.8$, showed high inductions at $\mathrm{pH} 7.2$ with Ga14 at 51 -fold, Ga13 at 33-fold, and Gaq/11 at 26-fold (Supplementary Table S2, Figure 1C).

Generally, the absolute induced signal is higher for all strains at $\mathrm{pH} 7.2$ compared to $\mathrm{pH} 4.8$ (Supplementary Table S2). The increase in background fluorescence at $\mathrm{pH} 7.2$, rather than a drop in the maximal induced reporter output, is the main reason explaining the 
overall diminished fold-change for the 3 best performing receptors at $\mathrm{pH} 4.8$. Interestingly, at pH 7.2 many previously poorly activated receptors showed an approximately 10-fold increase in absolute fluorescence levels in the induced state, while the background was only modestly elevated. This is exemplified for the 5-HT4 in the Ga14 background, where total induced reporter gene expression from 25 to 231 is observed while the background fluorescence only increased from 3.03 to 4.56 , ultimately shifting the fold-change of 5 -HT4 in the Ga14 background from 8.4 to 50.7 when comparing pH 4.8 and 7.2 (Supplementary Table S2, Figure 1C). Similar shifts can be observed for previously poorly induced 5HT4:Ga backgrounds (Gas/olf,Ga12, Ga13, Gaq/11, Ga14, Gao) at 4.8, which show foldchanges increased by up to 10 -fold at pH 7.2 (Supplementary Figure S1, Supplementary Table S2, Figure 1C).

Furthermore, at $\mathrm{pH} 7.2,5-\mathrm{HT} 1 \mathrm{~B}$ in the Gai3 background as well as 5-HT1A in Gaz background showed modest fold-changes of 1.5-fold, while 5-HT1E in the Gaz background reached 1.7 fold-change (Figure 1C, Supplementary Table S2). In comparison with previous serotonin receptor studies in yeast, 5-HT1A has been shown to couple to Gao, Gai2, Gai3, Ga14, and GPA1, while 5-HT1D has been coupled to Gai2 and Gai3 when expressed from high-copy plasmids and using a $\beta$-galactosidase or ZnGreen reporter assays (Brown et al., 2000; Nakamura et al., 2015). The observation that 5-HT1A couples to GPA1 was not supported by Ehrenworth et al. (Ehrenworth et al., 2017), and neither were we able to detect any changes in reporter output upon serotonin supplementation to strains expressing 5-HT1A, except in the Gaz background (Figure 1C). Furthermore, while we could not demonstrate activation of the $5-\mathrm{HT} 1 \mathrm{D}$ receptor at $\mathrm{pH} 4.8$ or 7.2 when the receptors were expressed from single-copy plasmids, our library screen corroborated the recent study by Kapolka et al. (Kapolka et al., 2020), showing promiscuity of 5-HT4 in coupling to all chimeric Ga proteins tested.

Taken together, our results show the functionality of 5-HT1A, 5-HT1B, 5-HT1E and 5HT4 in different chimeric GPA1/Ga backgrounds, with up to 64-fold induction in signalling output. Also, our study illustrates increased background fluorescence at $\mathrm{pH} 7.2$, especially for highly ligand induced Ga protein variants at $\mathrm{pH} 4.8$, and highly increased absolute overall fluorescence for variants poorly induced at $\mathrm{pH} 7.2$.

Chimeric Ga background impacts $E_{50}$ and sensitivity of 5-HT4 biosensing

In humans, serotonin receptors are believed to couple and activate inner-cellular responses primarily through the Gas protein (Berumen et al., 2012). To investigate the potential impact different chimeric Ga could have on serotonin sensing in yeast, we next studied the dose-response curves of the 5-HT4 receptor expressed together with the 12 different Ga background strains (Figure 1B-C). As genomic integration of serotonin GPCRs 
shows a more homogenous sensor signal compared to plasmid-based expression of serotonin GPCRs (Supplementary Figure S2), 5-HT4 was integrated into the 12 different $\mathrm{Ga}$ background strains, and reporter gene outputs obtained with serotonin stimulation between $0.01-1,000 \mu \mathrm{M}$ of serotonin (Figure 2). Next, serotonin concentrations yielding the half-maximal reporter output $\left(\mathrm{EC}_{50}\right)$ and sensitivity of serotonin biosensing (Hill coefficient) were obtained. Here, 5-HT4 expressed together with yeast native Ga protein GPA1 showed $E_{50}$ and Hill coefficient of $49.6 \mu \mathrm{M}$ and 1.53, respectively (Figure 2), while 5-HT4 expressed together with Gaz, Gai1/2 and Gai3 all yielded the lowest $\mathrm{EC}_{50}$ values of $8.33 \mu \mathrm{M}$, $17.17 \mu \mathrm{M}$ and $35.33 \mu \mathrm{M}$, respectively, and Ga12 and Ga14 showed the highest $\mathrm{EC}_{50}$ values $>200 \mu \mathrm{M}$ (Figure 2). With respect to cooperativity, all designs had Hill coefficients $>1$, with the highest seen for 5-HT4 expressed with Gaq/11 (2.23), Ga13 (2.07) and Gao (1.80).

Taken together, serotonin biosensing spanned approximately 25- and 2-fold difference in $\mathrm{EC}_{50}$ and sensitivity, respectively, by only using sensor strains with different 5 C-terminal residues of the yeast Ga protein GPA1 changed to C-terminal residues of human Ga proteins.

\section{A whole-cell biosensing workflow for serotonin}

Based on the operational range spanning almost three orders of magnitude, the low $E_{50}$, and high dynamic range (Figure 1C \& Figure 2), the chimeric GPA1/Gaz expressed together with 5-HT4 was next chosen as a platform design to explore the possibility of whole-cell biosensing of serotonin produced from yeast. Previously, it was shown that metabolically produced serotonin and melatonin can be sensed using their respective GPCRs (Ehrenworth et al., 2017; Shaw et al., 2019), and also that 5-HT4 could be used as a biosensor to discriminate between reporter outputs from a wild-type yeast and a serotoninproducing yeast, albeit with a modest sensor response of $\sim 2$-fold (Ehrenworth et al., 2017). Here, we set out to i) identify key parameters in developing a high-resolution and simple serotonin biosensing workflow using the biosensor based on chimeric GPA1/Gaz expressed together with $5-\mathrm{HT} 4$, and ii) construct a library of variant serotonin-producing yeast strains in order to validate biosensor performance.

Serotonin is produced from L-tryptophan via a 5-hydroxy-tryptophan (5-HTP) intermediate (Figure 3A)(Germann et al., 2016). To investigate possible activation of the 5HT4 sensor by precursor products, the biosensing strain was subjected to L-tryptophan and 5-HTP, as well as serotonin as a positive control over a range of $0.01 \mu \mathrm{M}-1,000 \mu \mathrm{M}$. Activation of the receptor, as inferred by fluorescence output, was only observed for serotonin, confirming the specificity of the 5-HT4 for serotonin over its precursors (Figure 3B). 
Next, as we previously observed a strong $\mathrm{pH}$-dependent effect on overall fluorescence and background fluorescence output from yeast strains expressing 5-HT4 together with Gaz (5-HT4:Gaz)(Figure 1C, Supplementary Figure S1, Supplementary Table S2), we sought to investigate the effect of $\mathrm{pH}$ on serotonin dose-response curves over a wider $\mathrm{pH}$ range. Consequently, the sensor strain was subjected to media with $\mathrm{pH}$ ranging from $\mathrm{pH} 2$ to $\mathrm{pH}$ 7. A yeast strain carrying only sfGFP under a TDH3 promoter served as a control and was subjected to the same $\mathrm{pH}$ conditions. Overall, the lowest $\mathrm{EC}_{50}$ value is observed at $\mathrm{pH} 7(0.01 \mu \mathrm{M})$ and $\mathrm{EC}_{50}$ values show an inverse proportional relationship with $\mathrm{pH}$ (Figure 3C). The broadest operational ranges as inferred by changes in sfGFP output are seen for the biosensing strain cultivated at $\mathrm{pH} 5$ and $\mathrm{pH} 6$, spanning from 0.1 to $100 \mu \mathrm{M}$, and from $0.01-10 \mu \mathrm{M}$, respectively. At $\mathrm{pH} 7$, the sensor strain reported changes in serotonin concentrations from 0.01 to $0.1 \mu \mathrm{M}$, while at $\mathrm{pH} 2$ no changes in reporter output were observed over the applied range of serotonin concentrations (Figure $3 \mathbf{C}$ ). Of importance, background fluorescence in the absence of serotonin is generally low for all $\mathrm{pH}$ conditions tested, with $\mathrm{EC}_{50}$ values decreasing by lowering the $\mathrm{pH}$ (Supplementary Table S3). However, at pH 6 and especially $\mathrm{pH} \mathrm{7,} \mathrm{background} \mathrm{fluorescence} \mathrm{increases,} \mathrm{as} \mathrm{also}$ observed with strains having plasmid-based expression of GPCRs (Figure $3 \mathbf{3}$, Supplementary Figure S1). Finally, the sfGFP control strain only shows serotoninindependent increase in fluorescence with increasing $\mathrm{pH}$ (Figure $\mathbf{3 C}$ ).

In addition to assessing $\mathrm{pH}$ effects, and acknowledging that serotonin produced from yeast cells is secreted to the cultivation medium, we tested if adding serotonin in yeast spent media would influence the signalling behaviour of the 5-HT4:Gaz sensor strain. For this purpose, spent media from a yeast base strain (BY4741) cultivated for $72 \mathrm{hrs}$ (72 h SM) was spiked with different concentrations of serotonin. Adding serotonin-spiked SM at $10 \%, 25 \%$ or $50 \%$ of the volume in the plate dilution step allowed us to evaluate spent media effects versus a control with serotonin spiked into water (MQ)(Figure 3D). At 10\%, only a slight decrease in fluorescence was observed between the cultivations with $\mathrm{MQ}$ control and $72 \mathrm{~h}$ $\mathrm{SM}$, as well as a modest increase in the $\mathrm{EC}_{50}$ from $4.00 \mu \mathrm{M}$ to $7.88 \mu \mathrm{M}$. At $25 \% \mathrm{SM}$, an $\mathrm{EC}_{50}$ increase from $2.59 \mu \mathrm{M}$ to $11.21 \mu \mathrm{M}$ was observed, while most notably, the $\mathrm{EC}_{50}$ increased from $1.70 \mu \mathrm{M}$ to $20.41 \mu \mathrm{M}$ when adding the ligand at 50\% SM (Figure 3D, Supplementary Table S4). Thus, taking into consideration the expected concentration of ligand produced, the ratio at which SM supernatant is added to the medium with the sensor strain should enable a simple biosensing workflow with adjustable $\mathrm{EC}_{50}$ values to the application of interest.

Lastly, we applied the workflow to screen a panel of yeast cells engineered to produce different levels of serotonin by randomly integrating variable numbers of expression 
cassettes for TPH enzyme into genomic Ty2 retrotransposon sites (Figure 3E-F)(Germann et al., 2016). Briefly, following random integration of open reading frames for TPH expression in transposable elements of the yeast genome (Germann et al., 2016; Maury et al., 2016), 24 randomly sampled colonies were grown for $72 \mathrm{hrs}$ before harvesting and adding supernatants to the sensor strain, followed by incubation for $4 \mathrm{hrs}$ and measurement of sfGFP fluorescence (Figure 3E). In parallel, the supernatants were analysed using HPLC to validate sfGFP reporter output as a proxy for absolute serotonin concentrations in the spent medium.

Taking into consideration acidification of yeast media over prolonged cultivations of strain BY4741 (Murakami et al., 2011), and the observed negative impact of spent media on maximum reporter output (Figure 3D), the reporter output from this screen was expected to be diminished compared to the serotonin-spike in titrations (Figure 2). Therefore, for the biosensing workflow, we decided to use synthetic complete medium at $\mathrm{pH} 4.9$, with supernatants from each of the 24 randomly sampled colonies of yeast strains engineered for serotonin production added at $10 \%$ volume. While adding spent medium at $10 \%$ infers a 10 fold dilution, the biosensor was able to resolve fluorescence outputs in these lower serotonin ranges (Figure 3F). From plotting biosensor fluorescence outputs against serotonin quantification as inferred from HPLC, a linear model fitted HPLC-measured serotonin concentrations and biosensor fluorescence from the 24 sampled strains $\left(R^{2}=0.91\right)$ (Figure 3F).

In summary, the engineered $5-\mathrm{HT} 4: G a z$ biosensing strain specifically senses serotonin, and can reliably detect serotonin in a facile and easy-adjustable (e.g. pH and spent medium) workflow compatible with high-throughput screening of libraries of yeast cells engineered to produce serotonin.

\section{Characterization of human 5-HT4 variants in yeast}

GPCR single-nucleotide polymorphisms (SNPs) are known to impact $\mathrm{EC}_{50}$ and agonist sensitivities in humans (Marti-Solano et al., 2020), and human variants of 5HT1a and MOR1 expressed in yeast have previously shown to reproduce Ga-dependent sensitivities to serotonin and morphine, respectively, as reported from mammalian cells (Bean et al., 2021; Nakamura et al., 2015).

Based on the biosensing platform developed in this study we next sought to examine the canonical isoform $b$ of human $5-\mathrm{HT} 4$, in comparison to human receptor variants or 'protein haplotypes' sourced from the 1,000 Genomes Project using the Haplosaurus tool browser via Ensembl (1000 Genomes Project Consortium et al., 2015; Spooner et al., 2018). From this data mining, 20 5-HT4 receptor variants were identified, of which 19 were cloned into yeast (Figure 4A). Nine of the tested variants were in the intracellular loops (including 
two on residue 137), four were located in the transmembrane domains, four on the Cterminus, one in the extracellular loop, and one in the N-terminus (Figure 4A).

Filtered data from Ensembl's Haplosaurus tool shows the distribution of variants across five different populations: African, American, East Asian, European and South Asian (Table 1). From this distribution, there are 218 non-reference genomes present in the dataset, showing different frequencies of variants in different populations (Table 1). Of these variants, some were computationally predicted to have deleterious or possibly damaging effects on receptor function ("D", Table 1). Because of this, we decided to introduce the receptor variants into the GPA1 background, as this background has a similar dynamic output range, but higher $\mathrm{EC}_{50}$ compared to the Gaz background (Figure 2). Next, for the 5HT4 dose-response study (Figure 2), receptor variants were assayed for serotonin responsiveness from $0.01-1,000 \mu \mathrm{M}$ serotonin, in addition to non-induced control without supplemented serotonin. $\mathrm{EC}_{50}$ values and Hill coefficients ranged from $5.05 \mu \mathrm{M}$ to $203.7 \mu \mathrm{M}$, and 0.67 to 3.20 , respectively (Figure $4 \mathrm{~B}$ ). The 5 -HT4 isoform b reference strain had an $E_{50}$ of $12.42 \mu \mathrm{M}$ and Hill coefficient of 1.13. while variants $24 \mathrm{~T}>\mathrm{M}(5.05 \mu \mathrm{M}), 260 \mathrm{~T}>\mathrm{N}(7.99$ $\mu \mathrm{M})$, and $231 \mathrm{R}>\mathrm{W}(9.94 \mu \mathrm{M})$ resulted in decreased $\mathrm{EC}_{50}$ values. Additionally, the $24 \mathrm{~T}>\mathrm{M}$ variant had an increased operational range as compared to reference (Figure 4B). Oppositely, the variants $372 \mathrm{C}>\mathrm{Y}, 15 \mathrm{G}>\mathrm{R}, 373 \mathrm{H}>\mathrm{P}, 348 \mathrm{~T}>\mathrm{N}$, and $361 \mathrm{~A}>\mathrm{V}$ variants resulted in minor increases in $E_{50}$ values $(1824-31.61 \mu \mathrm{M})$, while variants $27 \mathrm{~S}>\mathrm{L}, 321 \mathrm{R}>\mathrm{C}$, $137 \mathrm{R}>\mathrm{H}$, and $263 \mathrm{I}>\mathrm{N}$ variants resulted in notably higher $\mathrm{EC}_{50}$ values $(153.4-176.0 \mu \mathrm{M})$ as compared to the reference receptor. Interestingly, the $137 \mathrm{R}>\mathrm{H}$ variant had a considerably higher $\mathrm{EC}_{50}$ value than the $137 \mathrm{R}>\mathrm{C}$ variant $(174.6$ vs $43.06 \mu \mathrm{M})$ despite their shared residue location. For variants $302 \mathrm{Y}>\mathrm{F}$ and $255 \mathrm{~T}>\mathrm{I}$ no $\mathrm{EC}_{50}$ or Hill coefficient could be calculated due to their high detection limits and almost complete loss of function, respectively. Of the variants located in the transmembrane domains, $24 \mathrm{~T}>\mathrm{M}$ decreased the $\mathrm{EC}_{50}$ and increased the operational range, whereas $27 \mathrm{~S}>\mathrm{L}$, and $263 \mathrm{I}>\mathrm{N}$ resulted in $\mathrm{EC}_{50}$ values over $100 \mu \mathrm{M}$ (Figure 4A-B).

To further investigate the impact of the 5-HT4 variants, we tested our variant library with the 5-HT4 agonist, prucalopride succinate. Prucalopride is a high affinity, highly selective 5-HT4 receptor agonist designed to treat gastrointestinal disorders such as constipation (Briejer et al., 2001). Dose responses with prucalopride revealed a lower operational range with a reference $\mathrm{EC}_{50}$ of $87.48 \mu \mathrm{M}$ and a Hill coefficient of 0.88 , while the $24 \mathrm{~T}>\mathrm{M}$ variant maintained the increased dynamic range as observed with serotonin and a low $\mathrm{EC}_{50}$ of $8.92 \mu \mathrm{M}$ and Hill coefficient of 1.17 (Supplementary Figure S3). Additionally, of note, $302 Y>F$ maintained the loss-of-function, just as receptor variants $137 R>H, 137 R>C$, $223 \mathrm{~A}>\mathrm{D}, 255 \mathrm{~T}>\mathrm{I}, 263 \mathrm{l}>\mathrm{N}, 321 \mathrm{R}>\mathrm{C}$ also showed lower or loss-of-function in the presence of prucalopride. 
Ultimately, this study enabled reporting of dose-response parameters for 19 5-HT4 variants found in human populations spanning five demographic regions with serotonin and prucalopride. Importantly, in yeast, variants stimulated with serotonin displayed large differences in $\mathrm{EC}_{50}$ values $(5.05$ - $203.7 \mu \mathrm{M})$, cooperativity as inferred from Hill coefficients, as well as maximum reporter output, compared to the reference receptor.

\section{Discussion}

Here we show a combinatorial serotonin GPCR:Ga library screened at different pHs, and find 5-HT4, 5-HT1A, 5-HT1B, and 5-HT1E functional in yeast. In-depth characterization of serotonin-responsiveness of 5-HT4 receptors expressed in the different Ga backgrounds show $\mathrm{EC}_{50}$ values ranging from $8-250 \mu \mathrm{M}$, almost 2-fold changes in cooperativity, and up to 64-fold dynamic output ranges. We also present a high-resolution workflow sensing microbially produced serotonin and show that $\mathrm{pH}$ in spent cultivation medium strongly influences GPCR-mediated reporter outputs, allowing for simple adjustments of the sensing workflow according to concentration range of serotonin. Importantly, measuring microbially produced serotonin, the biosensor output strongly correlates with HPLC-measured serotonin concentrations, enabling finding best-producing strains at ease. Lastly, in addition to $\mathrm{Ga}, \mathrm{pH}$ and spent medium ratio, from a library of 195 -HT4 receptor variants we also demonstrate that single residue polymorphisms in serotonin GPCRs impact key reporter output parameters like $\mathrm{EC}_{50}$, cooperativity, agonist specificity, and maximum output. Taken together these findings enable rational tuning and further characterization of serotonin biosensing modalities.

Important findings from this study are the receptor functionality in yeast for 5-HT4 in all Ga protein backgrounds, and the modest fold-inductions (i.e. 1.5 - 1.7) for 5-HT1B in the Gai3 background, 5-HT1A in Gaz background, and 5-HT1E in the Gaz background. In agreement with Ehrenworth et al. (Ehrenworth et al., 2017) we found that, when coupled to yeast-native GPA1, the 5-HT1A, 5-HT1D 5-HT2B, 5-HT5A and 5-HT6 receptors were nonfunctional at both $\mathrm{pHs}$ tested in this study. While our findings largely abrogates recent findings related to Ga coupling and 5-HT receptor subtype, Brown et al., showed activation of 5-HT1A in chimeric and wild-type GPA1 Ga proteins (Brown et al., 2000). In our study, we were not able to demonstrate activation of the 5-HT1D receptor, and also not 5-HT1A in the GPA1 and Gai3 background previously reported (Brown et al., 2000; Nakamura et al., 2015). Likewise, previously, Yasi et al. expressed 5-HT4 in S. cerevisiae, and when assayed with serotonin and prucalopride they found that serotonin-activated receptors had a higher $\mathrm{EC}_{50}$ 
than prucalopride (Yasi et al., 2019), whereas our study found 5-HT4 to have higher $\mathrm{EC}_{50}$ for serotonin compared to prucalopride. Lastly, during preparation of this manuscript, $\mathrm{pH}$ dependent coupling of 5-HT4 for all 10 chimeric Ga was reported, in what was referred to as proton-gated coincidence detection (Kapolka et al., 2021). Interestingly, while Kapolka et al. observed 5-HT4 to signal through all Ga proteins at pH 7 and only Gaz and Gai1/2 at pH 5, we observed coupling to all tested $\mathrm{Ga}$ proteins at both $\mathrm{pH} 4.8$ and 7. Some of these divergent findings are likely attributable to different genetic backgrounds of sensor strains, the mode of expression (i.e. low copy plasmid, high copy plasmid, integration), and/or differences in reporters used (i.e. sfGFP, mTq2, ZsGreen, luciferase or $\beta$-galactosidase). Ultimately, different assay and strain designs impede direct comparison between studies calling for adoption of assay standards and protocols in regard to cultivation medium, timescales and background strains, when characterizing GPCRs in heterologous hosts like yeast.

While 5-HT1A, 5-HT1B, 5-HT1E or 5-HT4 were demonstrated functional in this study, reasons for non-functionality of the other 8 serotonin GPCRs in yeast could be manifold. Key points to be considered for future mitigations are endoplasmic reticulum processing issues, improper membrane localization, lack of coupling receptors to Ga proteins, and suboptimal sterol environment compared to native human host cells. While adding signaling sequences seems to yield mixed results (Dirnberger and Seuwen, 2007; Fukutani et al., 2012), changing the lipid composition from yeast native ergosterol to sterol synthesis has yielded promising results, shown in the activation of previously non-functional opioid receptors in yeast (Bean et al., 2021). Likewise, varying tissue and organ expression (Figure 1C), coincidence detection (Kapolka et al., 2021), and even biased signaling (Choudhary and Loewen, 2016), affect GPCR signaling, and should be considered for further investigation of 5-HT receptor signaling in yeast.

Furthermore, we demonstrated the impact of 19 different polymorphisms of 5-HT4 found in the 1,000 Human Genomes Project on signaling behavior, and compared them to the reference 5-HT4 sequence (1000 Genomes Project Consortium et al., 2015). Previously, a few 5-HT4 variants have been studied in mammalian heterologous systems. For instance, when expressed in 5-HT4 isoform g, 302Y>F decreased the affinity of GR113808 to the receptor by 13 -fold but did not affect serotonin induced activity, though it decreased receptor expression (Rivail et al., 2004; Vass et al., 2019). Here, in the S. cerevisiae platform, the variant $302 Y>F$ results in a loss of function receptor in the presence of serotonin and prucalopride (Figure 4, Supplementary Figure S3). Furthermore, and of pharmacokinetic relevance, it has been hypothesized that residue $302 \mathrm{Y}$ is an important stabilizing residue for agonist and antagonist binding to the 5-HT4 receptor (Mialet et al., 2000; Rivail et al., 2004). From the Haplosaurus tool (Spooner et al., 2018), we observed that the South Asian 
individual was heterozygous for the $302 \mathrm{Y}>\mathrm{F}$ variant, which could have implications to responsiveness of 5 - $\mathrm{HT} 4$ targeting drugs. While we did not study the binding affinity of the $302 \mathrm{Y}>\mathrm{F}$ variant or its expression in the $\mathrm{S}$. cerevisiae platform as performed by Rivail et al. (Rivail et al., 2004), our findings highlight that residue $302 Y$ is important for serotonin signaling via $5-\mathrm{HT} 4$. While the yeast platform cannot be $1: 1$ paralleled to human cells and GPCR signaling, the difference in activity and $\mathrm{EC}_{50}$ values in the receptor variants could indicate important shifts in receptor activity and expression.

For future directions, we envision the study of polymorphisms of receptor variants for better sequence- and structure-guided engineering of GPCRs to flourish. As demonstrated herein, changes of one amino-acid in a receptor can vastly influence the signaling behavior of GPCR receptors, and we highlight yeast as a relevant chassis for mutational studies coupled to machine learning approaches, ultimately enabling better understanding of GPCR specificity, expression, pharmacokinetic properties, and finally allow for a more targeted engineering of advanced biosensors Additionally, establishing yeast as a platform to study mammalian receptor polymorphisms could allow for a high-throughput platform for flagging possible variant-related drug activity impacts, and thus serve a purpose in hit-to-lead drug discovery regimes. In terms of human health, such findings should then further extent yeast GPCR biosensing to real-life applications, as recently shown for GPCR-based feedbackregulation loop in an engineered probiotic yeast Saccharomyces boulardii for the destruction of extracellular ATP in mice guts (Scott et al., 2021; Shaw et al., 2019). We anticipate that such opportunities will be explored further and form the basis for many more GPCR-based biosensors to be developed and applied in the near future.

\section{Acknowledgements}

This study was supported by Novo Nordisk Foundation Copenhagen Bioscience Ph.D. grant No. NNF19CC0035454 and NNF20SA0035588 and Novo Nordisk Foundation Center for Biosustainability grant number NNF20CC0035580. Authors also would like to thank Luke W. Johnston for help with R scripts, Marcus Deichman for fruitful discussions, as well as Lars Schrübbers for technical assistance related to analytical serotonin measurements.

\section{Author Contributions}

$\mathrm{BL}, \mathrm{EDJ}$ and MKJ conceived the study. BL and EEH-S performed all the experiments and performed all the data analysis. BL, EEH-S, EDJ, TJ and CNJ designed and constructed all 
plasmids and strains. BL, EEH-S and MKJ wrote the manuscript. All authors approved the manuscript.

\section{Declaration of Interests}

The authors declare no competing interests.

\section{Figure legends}

Figure 1: Exploring serotonin GPCR functionality in yeast. A) Heatmap of transcripts of serotonin GPCR expression in human tissues and organs from Human Protein Atlas (Uhlén et al., 2015). Color key indicates relative expression levels normalized by row. B) Schematic of engineered yeast mating pathway (Shaw et al., 2019), coupled to human serotonin GPCRs. Serotonin binds to 5-HT class of GPCRs, the associated engineered GPA1-based chimeric Ga protein dissociates into one Ga subunit, and a Gßy dimer to induce the MAPkinase cascade (Ste5/Ste7/Ste11), which in turn activates a chimeric transcription factor (chimeric TF), binding to an synthetic promoter to enable expression of superfolder green fluorescent protein (sfGFP). C) Heatmap of 12 serotonin GPCRs expressed from centromeric plasmids in 12 different Ga background yeast strains. Fold-change shown in color (FC) represents the ratio of fluorescence between induced (100 $\mu \mathrm{M}$ serotonin) and uninduced state ( $0 \mu \mathrm{M}$ serotonin). FC values represent the average of triplicate median values sampled by flow cytometry with 10,000 events analyzed for each triplicate in both induced and non-induced conditions. Note that breaks in the color range for $1 \mathrm{C}$ are not equidistant for the lower end of the scale to allow for representation of the lower-induced variants.

Figure 2. Dose-response curves of $5-\mathrm{HT} 4$ coupling to chimeric Ga proteins. Yeast strains expressing 5-HT4 in combination with 12 different Ga backgrounds, namely yeast GPA1, truncated GPA1 (tGPA1), or any of the 10 different GPA1/Ga chimera (Brown et al., 2000; Shaw et al., 2019). Strains were cultivated in control medium without serotonin, or $0.01-1000 \mu \mathrm{M}$ serotonin, and sfGFP reporter outputs recorded following $4 \mathrm{hrs}$. All data points represent the median fluorescence intensity of three technical replicates $(10,000$ events each), of which the mean $+/$ - standard deviation was calculated. Data was fitted to a 
variable slope four-parameter curve fitting model, from which $\mathrm{EC}_{50}$ and Hill slope values were calculated, except for the tGPA1 background strain serving as a negative control. AU $=$ arbitrary units. n.a. $=$ not applicable.

Figure 3. A workflow for semi-throughput characterization of serotonin accumulation in engineered yeast cells. A) Serotonin is produced from L-tryptophan and $\mathrm{BH} 4$ cofactor via 5-hydroxy-L-tryptophan using tryptophan hydroxylase (TPH) and 5-hydroxy-L-tryptophan decarboxylase (DDC) enzymes. B) Dose-response curves of 5-HT4:Gaz sensor strain upon induction with serotonin, L-tryptophan or 5-HTP. C) Effect of media with different $\mathrm{pH}$ on the Gaz+5-HT4 sensor strain and a constitutively sfGFP expressing yeast base strain, incubated with serotonin D) Dose-response curves of adding spiked spent media (72 h SM) or serotonin spiked water (MQ) at different volumetric \%-ages added to the sensor strain. E) Workflow for sensing yeast-produced serotonin. Serotonin producing cells are incubated for $72 \mathrm{hrs}$, the supernatant is spun down, added to, and incubated with the sensor strain expressing 5-HT4:Gaz sensor, and sfGFP expression ultimately screened using flow cytometer as a proxy for serotonin production. F) Correlation of HPLC-based quantification of serotonin and sfGFP expression via Gaz+5-HT4 of serotonin producing yeast strains carrying multiple copies of TPH $(x n)$. Data were fitted with a simple linear regression model. For B) and D), each data point consists of technical triplicates of 10,000 events, for C) 6,500 events were recorded and F) 5,000 events were analysed for each triplicate. For all data panels, the median fluorescence of each triplicate was calculated, and mean \pm standard deviation shown.

Figure 4. Characterization of 5-HT4 serotonin GPCR variants from human genomes. A) Snake-plot of 5-HT4 isoform b mutational landscape showing location of analyzed variants on the protein. All screened variants had a single mutated amino acid. Two different variants were screened separately on residue 137 . B) Dose responses for the 5-HT4b isoform reference receptor and 19 variants in GPA1 background. Yeast strains expressing singleamino acid variant GPCRs were induced with $0.01 \mu \mathrm{M}-1,000 \mu \mathrm{M}$ serotonin in addition to a non-induced "0" control. sfGFP was measured following 4 hrs of incubation with serotonin. All data points represent median fluorescence intensity of three technical replicates $(10,000$ events each), from which the mean $+/$ - the standard deviation was calculated. $A U=$ arbitrary units, n.a. = not applicable. Data was fitted to a variable slope four-parameter curve fitting model, from which $\mathrm{EC}_{50}$ and Hill slope values were calculated. Dose-response curves show the tested variant (solid line) and the reference receptor (dashed line). 


\section{Tables}

\begin{tabular}{|c|c|c|c|c|c|c|c|}
\hline Protein Haplotpye/Nariant & Flags & Count & African & American & East Asian & European & South Asian \\
\hline Reference & & 5799 & 1208 & 688 & 1004 & 1003 & 970 \\
\hline $372 \mathrm{C}>\mathrm{Y}$ & & 158 & 95 & 4 & 0 & 0 & 0 \\
\hline $24 \mathrm{~T} \gg \mathrm{M}$ & & 9 & 2 & 1 & 0 & 0 & 0 \\
\hline $187 \mathrm{M}: \mathrm{T}$ & $\mathrm{D}$ & 4 & 1 & 0 & 0 & 0 & 0 \\
\hline $27 \mathrm{~S}>\mathrm{L}$ & & 2 & 0 & 0 & 0 & 1 & 1 \\
\hline $321 \mathrm{R}>\mathrm{C}$ & $D$ & 2 & 0 & 0 & 2 & 0 & 0 \\
\hline $373 \mathrm{H}>\mathrm{P}$ & & 2 & 0 & 0 & 0 & 0 & 0 \\
\hline $231 R>W$ & $D$ & 2 & 0 & 1 & 0 & 0 & 0 \\
\hline $302 \gamma, F$ & D & 1 & 0 & 0 & 0 & 0 & 1 \\
\hline $255 T>1$ & $D$ & 1 & 1 & 0 & 0 & 0 & 0 \\
\hline $348 \mathrm{~T}>\mathrm{N}$ & & 1 & 0 & 0 & 0 & 0 & 1 \\
\hline $258 A>T$ & $D$ & 1 & 1 & 0 & 0 & 0 & 0 \\
\hline $2631>N$ & D & 1 & 0 & 0 & 1 & 0 & 0 \\
\hline $214 \mathrm{R}>\mathrm{H}$ & D & 1 & 0 & 0 & 0 & 0 & 1 \\
\hline $223 A=D$ & D & 1 & 0 & 0 & 0 & 0 & 1 \\
\hline
\end{tabular}

Table 1. Demographic distribution of human 5-HT4 non-synonymous polymorphisms.

Demographic distribution of 5-HT4b haplotypes adapted from 1,000 Genomes data using the Haplosaurus tool (Spooner et al., 2018). Haplosaurus annotated variants with a 'D' in the 'Flags' column that are flagged as being deleterious (SIFT) or probably damaging (PolyPhen-2). Frequency data comes from the GRCh38 reference genome from the Genome reference Consortium using data from the 1,000 Genomes Project phase 3. 


\section{Method Details}

\section{Cultivation of E.Coli}

Chemically competent Escherichia coli DH5a strain was used for plasmid propagation and cloning. E.Coli strains were grown in 2xYT media, supplemented with 100 $\mu \mathrm{g} / \mathrm{mL}$ ampicillin at $250 \mathrm{rpm}$.

\section{Cultivation of yeast}

Saccharomyces cerevisiae BY4741 strains described in this study were grown in synthetic complete media $(6.7 \mathrm{~g} / \mathrm{L}$ yeast nitrogen base without amino acids with appropriate drop-out medium supplement) with appropriate auxotrophic selection, supplemented with 20 $\mathrm{g} / \mathrm{L}$ glucose. Yeast in pre-culture tubes was grown at $30^{\circ} \mathrm{C}$ and $250 \mathrm{rpm}$, while incubation in 96-well deep well plates took place at at $30{ }^{\circ} \mathrm{C}$ and $300 \mathrm{rpm}$. The complete list of all synthetic genes used can be found in Supplementary Table S5.

\section{GPCR and 5-HT4b variant sourcing}

The protein sequence of GPCRs was selected on uniprot.com and translated into nucleic acid sequence using the EMBOSS Backtranseq tool (Madeira et al., 2019; UniProt Consortium, 2021) and ordered as biobricks via Twist Bioscience.

For human 5-HT4b variants The identified transcript for human 5HT4b (ENST00000377888) was identified on Ensembl through the International Genome Sample Resource database to find information on global population variants and distribution (1000 Genomes Project Consortium et al., 2015). Single amino acid variants and their population frequency were identified through the Ensembl genome browser using the Haplosaurus tool for the previously specified transcript ID (Spooner et al. 2018). Due to the codon-optimized $5 \mathrm{HT} 4 \mathrm{~b}$ receptor, variants were designed with the amino acid variation of interest irrespective of base pair changes. Of the 205 -HT4b single amino acid variants listed on the Haplosaurus protein-haplotype browser on Ensembl, 19 were tested in S. cerevisiae due to a cloning issue of one of the variants.

\section{Plasmid construction and transformation into E. Coli}

All plasmids in this study were cloned using USER ${ }^{\mathrm{TM}}$ (uracil specific excision reagent) cloning (New England Biolabs) and the EasyClone method (Jessop-Fabre et al., 2016). Genetic parts for assembly into plasmids and USER ${ }^{\mathrm{TM}}$ vector plasmids were amplified using PhusionU polymerase (Thermo Fisher Scientific). Plasmids containing the GPCRs had a Kozak sequence (AAAACA) in front of the start codon of the receptor. 
Synthetic genes were ordered from TWIST Bioscience, custom oligos were ordered from IDT or used from previous publications (Jakočiūnas et al. 2015). The complete list of all gBlocks and plasmids and used can be found in Supplementary Table S5, S6, and S7. Plasmids were transformed into chemically competent DH5a strain by heat-shocking for 45 seconds at $42^{\circ} \mathrm{C}$ and recovered on LB plates supplemented with $100 \mu \mathrm{g} / \mathrm{mL}$ Ampicillin.

\section{Yeast transformations}

Plasmids and linear DNA parts for integration were transformed into yeast using the lithium acetate/single-stranded carrier DNA/PEG method (Gietz and Schiestl, 2007).

Construction of yeast strains

For plasmid based GPCR expression, library strains were constructed by transforming plasmids containing the respective serotonin GPCR under a CCW12 promoter, and a HIS3 marker. Plasmids were transformed into yeast strains yWS2261-yWS2272, representing optimized sensor strains with different Ga protein backgrounds (Shaw et al., 2019). Transformed yeast cells were selected on SC-HIS plates.

For integration of GPCR into the yeast genome, plasmids with overlap to genomic sites as described by Jessop-Fabre et al. were engineered to contain the respective genetic sequence to be integrated (serotonin GPCR, 5-HT4(b) variant) (Jessop-Fabre et al. 2016). Plasmids were Notl digested for $4 \mathrm{hrs}$, the Notl enzyme was heat-inactivated and linear fragments were integrated into yeast genomic sites with the help of a Cas9 plasmid and a gRNA plasmid targeting the respective integration site (Jessop-Fabre et al., 2016).

The serotonin production strains were constructed as described previously (Germann et al., 2016). Plasmid pCfB9221 containing enzymes HsDDC and SmTPH was previously constructed and integrated into XI-3 (Germann et al., 2016). Cofactor enzymes RnPTS and RnSPR, as well as PaPCBD1 and RnDHPR were cloned on 2 plasmids and integrated into EasyClone sites X-4 and XII-4, respectively. Additionally, plasmid p2772, constructed by (Germann et al., 2016), containing SmTPH with overlap to TY2 sites, was integrated in the yeast TY2 sites.

The complete list of all yeast strains constructed can be found in Supplementary Table S8.

\section{Biosensor assay}

Yeast strains were freshly plated and grown on SC plates with respective auxotrophy if required. On day 1 , a single colony of a sensing strain was inoculated in SC media with the respective auxotrophy if needed and grown for $24 \mathrm{hrs}$. On day 2, the culture was diluted 1:100 in SC media with or without auxotrophy and grown for 16 hrs. On day 3, the culture 
was diluted 1:50 in SC media with or without auxotrophy and grown for two hrs. In 96-well flat-bottom plate, $20 \mathrm{uL}$ of ligand dissolved in either milliQ water, serotonin-producing yeast supernatant or spent media (SigmaAldrich: Serotonin hydrochloride H9523-100MG, Ltryptophan T0254-1G, 5-hydroxy-L-tryptophan H9772-1G) was combined with $180 \mu \mathrm{L}$ of culture of a sensing strain, except for the experiment in Figure 3D, where additionally ratios of 50 $\mathrm{uL}: 150 \mu \mathrm{L}$ and $100 \mu \mathrm{L}: 100 \mathrm{uL}$ ligand:biosensor were used. Note that different serotonin concentrations (that means $10,000 \mu \mathrm{M}, 4,000 \mu \mathrm{M}$ and 2,000 $\mu \mathrm{M}$ that were added at $10 \%$, $25 \%$ or $50 \%$ volume, resulting in $1000 \mu \mathrm{M}$ in-plate-concentration in the highest dilution step. The 96-well plate was covered with a PCR foil and incubated for another $4 \mathrm{hrs}$ at $30^{\circ} \mathrm{C}$ and $300 \mathrm{rpm}$. Plates were chilled at $4{ }^{\circ} \mathrm{C}$ until ready for flow cytometry analysis. The same experimental set-up was used for the dose response curves with prucalopride succinate dissolved in milliQ water (SigmaAldrich: Prucalopride succinate AMBH2D6FB305-100MG). pH of the SC-media ranged between 4.7 and 5.3 during all experiments apart from the $\mathrm{pH}$ experiment (Figure $\mathbf{3 C}$ ).

\section{Flow cytometry analysis}

Flow cytometry analysis was performed on the Miltenyi MACSQuant VYB, using medium mixing and fast running mode. 10,000 events were recorded for each well analyzed, unless otherwise specified. Cells were gated for singlets in exponential phase, and 10,000 events within the singlet gate were recorded for each well analyzed, apart from Figure 3C, where 6,500 events were recorded, and Figure 3F, where 5000 events were analyzed.

\section{Serotonin production in yeast}

Serotonin producing strains were inoculated from a single colony and grown for 16 hrs in SC-URA media ( $\mathrm{pH}$ 4.9). Cultures were diluted 1:50 and grown for 72 hrs in SC-URA media in 96-well deep well culture plates. Supernatants were harvested by spinning at 4000 rpm for $5 \mathrm{~min}$. Supernatants were carefully transferred into 96 -well plates, covered with aluminum foil and stored at $-80^{\circ} \mathrm{C}$ for flow cytometry or HPLC analysis.

HPLC analysis of serotonin production strains

Analysis of serotonin was done on the Thermo Scientific ${ }^{\text {TM }}$ UltiMate $^{\text {TM }} 3000$. Solvent A was $0.05 \%$ acetic acid, solvent B Acetonitrile. The column used was the Agilent Zorbax C18 4.6x100mm 30l5-Micron with a Phenomenex AFO-8497 filter. The solvent gradient can was:

\begin{tabular}{|l|l|l|l|}
\hline Time & $\begin{array}{l}\text { Flow } \\
{[\mathrm{ml} / \mathrm{min}]}\end{array}$ & $\% \mathrm{~A}$ & $\% \mathrm{~B}$ \\
\hline
\end{tabular}




\begin{tabular}{|r|r|l|l|}
\hline 0 & 1.000 & 95.0 & 5.0 \\
\hline 1.5 & 1.000 & 88.0 & 12.0 \\
\hline 2.5 & 1.000 & 88.0 & 12.0 \\
\hline 4.5 & 1.000 & 70.0 & 30.0 \\
\hline 5.5 & 1.000 & 70.0 & 30.0 \\
\hline 8.0 & 1.000 & 30.0 & 70.0 \\
\hline 9.0 & 1.000 & 30.0 & 70.0 \\
\hline 9.5 & 1.000 & 95.0 & 5.0 \\
\hline 11.0 & end & end & \\
\hline
\end{tabular}

HPLC values were determined according to two standard curves between 0 and 100 $\mathrm{UM}$ serotonin hydrochloride in $\mathrm{MQ}$, one run before and one after the samples between 0 and $100 \mu \mathrm{M}$ serotonin hydrochloride in $\mathrm{MQ}$ using the using Chromeleon ${ }^{\mathrm{TM}}$ Chromatography Data System (CDS) Software.

\section{Data analysis}

Data analysis was done in $\mathrm{R}$ programming language usingR studio, with customised $\mathrm{R}$ scripts, making use of the tidyverse, flowCore and pheatmap packages (Team 2020; RStudio Team 2020; Wickham et al. 2019; Hahne et al. 2009; Kolde 2017).

For dose response curves with flow cytometry data and the heatmap in Figure 1C, data were always obtained in triplicate and median fluorescence values of each triplicate (consisting of min. 5000 events as described in the biosensor assay section) were calculated, of which the mean and standard deviation was calculated. Mean and standard deviation were exported to GraphPadPrism to create dose-response curves. Curve fitting was done in GraphPadPrims with the variable 4 parameter model, apart from Figure 3C, in which curves were fitted with the three-parameter model. Only curve fits $>0.9$ were considered, if lower, or $\mathrm{EC}_{50}$ and hillslopes could not be calculated, "n.a." is stated. For Figure 3F, simpler linear regression in GraphPadPrism was used (GraphPad Software, San Diego, California USA). For Figure 1C, fold-changes were calculated by dividing the induced state value fluorescence intensity by the uninduced state fluorescence after calculating the mean of 3 median values as described previously. Sensor strains with fold-change values $>1.4$ were considered functional.

HPLC data were analysed using Chromeleon ${ }^{\mathrm{TM}}$ Chromatography Data System (CDS) Software. The snake plot was constructed using Protter (Omasits et al., 2014) and with structure 5HT4R_HUMAN imported from UniProt (UniProt Consortium 2021). 
For the transcript heatmap in Fig. 1A tissue isoform-RNA data was sourced from the Human Protein Atlas database (Uhlén et al. 2015). Data is available from proteinatlas.org, version 20.1. Several of the genes of interest produced splice variants so corresponding Ensembl transcript IDs were selected by amino acid similarity to the UniProt canonical sequence. In the case where several splice variants matched the canonical sequence, transcript levels were compared in GTEx and the transcript with higher tissue expression was selected (Carithers et al. 2015). Non-tissue samples were filtered out from the dataset. Heatmaps were made with the R package 'pheatmap' and normalized by row (Hahne et al., 2009; Kolde, 2017; Team, 2020; Wickham et al., 2019). Transcript IDs for receptors can be found in Supplementary Table S1.

All scripts for data analysis can be found at https://github.com/betlen/serosense.

\section{References}

1000 Genomes Project Consortium, Auton, A., Brooks, L.D., Durbin, R.M., Garrison, E.P., Kang, H.M., Korbel, J.O., Marchini, J.L., McCarthy, S., McVean, G.A., et al. (2015). A global reference for human genetic variation. Nature $526,68-74$.

Bean, B.D.M., Mulvihill, C.J., Garge, R.K., Boutz, D.R., Rousseau, O., Floyd, B.M., Cheney, W., Gardner, E.C., Ellington, A.D., Marcotte, E.M., et al. (2021). Functional expression of opioid receptors and other human GPCRs in yeast engineered to produce human sterols.

Berger, M., Gray, J.A., and Roth, B.L. (2009). The expanded biology of serotonin. Annu. Rev. Med. 60, 355-366.

Berumen, L.C., Rodríguez, A., Miledi, R., and García-Alcocer, G. (2012). Serotonin receptors in hippocampus. ScientificWorldJournal 2012, 823493.

Briejer, M.R., Bosmans, J.P., Van Daele, P., Jurzak, M., Heylen, L., Leysen, J.E., Prins, N.H., and Schuurkes, J.A. (2001). The in vitro pharmacological profile of prucalopride, a novel enterokinetic compound. Eur. J. Pharmacol. 423, 71-83.

Brown, A.J., Dyos, S.L., Whiteway, M.S., White, J.H., Watson, M.A., Marzioch, M., Clare, J.J., Cousens, D.J., Paddon, C., Plumpton, C., et al. (2000). Functional coupling of mammalian receptors to the yeast mating pathway using novel yeast/mammalian $\mathrm{G}$ protein alpha-subunit chimeras. Yeast 16,11-22.

Choudhary, P., and Loewen, M.C. (2016). Evidence of a role for S. cerevisiae a-arrestin Art1 (Ldb19) in mating projection and zygote formations. Cell Biol. Int. 40, 83-90.

Conklin, B.R., and Bourne, H.R. (1993). Structural elements of Ga subunits that interact with Gßy, receptors, and effectors. Cell 73, 631-641.

Dirnberger, D., and Seuwen, K. (2007). Signaling of human frizzled receptors to the mating pathway in yeast. PLoS One 2, e954.

Dohlman, H.G., Song, J., Ma, D., Courchesne, W.E., and Thorner, J. (1996). Sst2, a negative regulator of pheromone signaling in the yeast Saccharomyces cerevisiae: expression, localization, and genetic interaction and physical association with Gpa1 (the G- 
protein alpha subunit). Mol. Cell. Biol. 16, 5194-5209.

Ehrenworth, A.M., Claiborne, T., and Peralta-Yahya, P. (2017). Medium-Throughput Screen of Microbially Produced Serotonin via a G-Protein-Coupled Receptor-Based Sensor. Biochemistry 56, 5471-5475.

Fukutani, Y., Nakamura, T., Yorozu, M., Ishii, J., Kondo, A., and Yohda, M. (2012). The Nterminal replacement of an olfactory receptor for the development of a yeast-based biomimetic odor sensor. Biotechnol. Bioeng. 109, 205-212.

Galanie, S., Thodey, K., Trenchard, I.J., Filsinger Interrante, M., and Smolke, C.D. (2015). Complete biosynthesis of opioids in yeast. Science 349, 1095-1100.

Germann, S.M., Baallal Jacobsen, S.A., Schneider, K., Harrison, S.J., Jensen, N.B., Chen, X., Stahlhut, S.G., Borodina, I., Luo, H., Zhu, J., et al. (2016). Glucose-based microbial production of the hormone melatonin in yeast Saccharomyces cerevisiae. Biotechnol. J. 11, 717-724.

Gietz, R.D., and Schiestl, R.H. (2007). High-efficiency yeast transformation using the LiAc/SS carrier DNA/PEG method. Nat. Protoc. 2, 31-34.

GraphPad Software, San Diego, California USA.

Hahne, F., LeMeur, N., Brinkman, R.R., Ellis, B., Haaland, P., Sarkar, D., Spidlen, J., Strain, E., and Gentleman, R. (2009). flowCore: a Bioconductor package for high throughput flow cytometry. BMC Bioinformatics 10, 106.

Jessop-Fabre, M.M., Jakočiūnas, T., Stovicek, V., Dai, Z., Jensen, M.K., Keasling, J.D., and Borodina, I. (2016). EasyClone-MarkerFree: A vector toolkit for marker-less integration of genes into Saccharomyces cerevisiae via CRISPR-Cas9. Biotechnol. J. 11, 1110-1117.

Kapolka, N.J., Taghon, G.J., Rowe, J.B., Morgan, W.M., Enten, J.F., Lambert, N.A., and Isom, D.G. (2020). DCyFIR: a high-throughput CRISPR platform for multiplexed G proteincoupled receptor profiling and ligand discovery. Proc. Natl. Acad. Sci. U. S. A. 117, 1311713126.

Kapolka, N.J., Rowe, J.B., Taghon, G.J., Morgan, W.M., O'Shea, C.R., and Isom, D.G. (2021). Proton-gated coincidence detection is a common feature of GPCR signaling. Proc. Natl. Acad. Sci. U. S. A. 118.

King, K., Dohlman, H.G., Thorner, J., Caron, M.G., and Lefkowitz, R.J. (1990). Control of yeast mating signal transduction by a mammalian beta 2-adrenergic receptor and Gs alpha subunit. Science 250, 121-123.

Kolde, R. (2017). Pheatmap: pretty heatmaps. 2015. R Package Version.

Leberer, E., Dignard, D., Harcus, D., Thomas, D.Y., and Whiteway, M. (1992). The protein kinase homologue Ste20p is required to link the yeast pheromone response G-protein beta gamma subunits to downstream signalling components. The EMBO Journal 11, 4815-4824.

Lengger, B., and Jensen, M.K. (2020). Engineering G protein-coupled receptor signalling in yeast for biotechnological and medical purposes. FEMS Yeast Res. 20.

Luo, X., Reiter, M.A., d'Espaux, L., Wong, J., Denby, C.M., Lechner, A., Zhang, Y., Grzybowski, A.T., Harth, S., Lin, W., et al. (2019). Complete biosynthesis of cannabinoids and their unnatural analogues in yeast. Nature 567, 123-126. 
Madeira, F., Park, Y.M., Lee, J., Buso, N., Gur, T., Madhusoodanan, N., Basutkar, P., Tivey, A.R.N., Potter, S.C., Finn, R.D., et al. (2019). The EMBL-EBI search and sequence analysis tools APIs in 2019. Nucleic Acids Res. 47, W636-W641.

Manabe, N., Wong, B.S., and Camilleri, M. (2010). New-generation 5-HT4 receptor agonists: potential for treatment of gastrointestinal motility disorders. Expert Opin. Investig. Drugs 19, 765-775.

Marinissen, M.J., and Gutkind, J.S. (2001). G-protein-coupled receptors and signaling networks: emerging paradigms. Trends Pharmacol. Sci. 22, 368-376.

Marti-Solano, M., Crilly, S.E., Malinverni, D., Munk, C., Harris, M., Pearce, A., Quon, T., Mackenzie, A.E., Wang, X., Peng, J., et al. (2020). Combinatorial expression of GPCR isoforms affects signalling and drug responses. Nature 587, 650-656.

Maury, J., Germann, S.M., Baallal Jacobsen, S.A., Jensen, N.B., Kildegaard, K.R., Herrgård, M.J., Schneider, K., Koza, A., Forster, J., Nielsen, J., et al. (2016). EasyCloneMulti: A Set of Vectors for Simultaneous and Multiple Genomic Integrations in Saccharomyces cerevisiae. PLoS One 11, e0150394.

Mialet, J., Dahmoune, Y., Lezoualc'h, F., Berque-Bestel, I., Eftekhari, P., Hoebeke, J., Sicsic, S., Langlois, M., and Fischmeister, R. (2000). Exploration of the ligand binding site of the human 5-HT(4) receptor by site-directed mutagenesis and molecular modeling. Br. J. Pharmacol. 130, 527-538.

Mukherjee, K., Bhattacharyya, S., and Peralta-Yahya, P. (2015). GPCR-Based Chemical Biosensors for Medium-Chain Fatty Acids. ACS Synth. Biol. 4, 1261-1269.

Murakami, C.J., Wall, V., Basisty, N., and Kaeberlein, M. (2011). Composition and acidification of the culture medium influences chronological aging similarly in vineyard and laboratory yeast. PLoS One 6, e24530.

Nakamura, Y., Ishii, J., and Kondo, A. (2015). Applications of yeast-based signaling sensor for characterization of antagonist and analysis of site-directed mutants of the human serotonin 1A receptor. Biotechnol. Bioeng. 112, 1906-1915.

Nichols, D.E., and Nichols, C.D. (2008). Serotonin receptors. Chem. Rev. 108, 1614-1641.

Omasits, U., Ahrens, C.H., Müller, S., and Wollscheid, B. (2014). Protter: interactive protein feature visualization and integration with experimental proteomic data. Bioinformatics 30 , 884-886.

Pándy-Szekeres, G., Munk, C., Tsonkov, T.M., Mordalski, S., Harpsøe, K., Hauser, A.S., Bojarski, A.J., and Gloriam, D.E. (2018). GPCRdb in 2018: adding GPCR structure models and ligands. Nucleic Acids Res. 46, D440-D446.

Price, L.A., Kajkowski, E.M., Hadcock, J.R., Ozenberger, B.A., and Pausch, M.H. (1995). Functional coupling of a mammalian somatostatin receptor to the yeast pheromone response pathway. Mol. Cell. Biol. 15, 6188-6195.

Rivail, L., Giner, M., Gastineau, M., Berthouze, M., Soulier, J.-L., Fischmeister, R., Lezoualc'h, F., Maigret, B., Sicsic, S., and Berque-Bestel, I. (2004). New insights into the human 5-HT4 receptor binding site: exploration of a hydrophobic pocket. Br. J. Pharmacol. 143, 361-370.

Scott, B.M., Gutiérrez-Vázquez, C., Sanmarco, L.M., da Silva Pereira, J.A., Li, Z., Plasencia, 
A., Hewson, P., Cox, L.M., O'Brien, M., Chen, S.K., et al. (2021). Self-tunable engineered yeast probiotics for the treatment of inflammatory bowel disease. Nat. Med.

Shaw, W.M., Yamauchi, H., Mead, J., Gowers, G.-O.F., Bell, D.J., Öling, D., Larsson, N., Wigglesworth, M., Ladds, G., and Ellis, T. (2019). Engineering a Model Cell for Rational Tuning of GPCR Signaling. Cell 177, 782-796.e27.

Spooner, W., McLaren, W., Slidel, T., Finch, D.K., Butler, R., Campbell, J., Eghobamien, L., Rider, D., Kiefer, C.M., Robinson, M.J., et al. (2018). Haplosaurus computes protein haplotypes for use in precision drug design. Nat. Commun. 9, 4128.

Syrovatkina, V., Alegre, K.O., Dey, R., and Huang, X.-Y. (2016). Regulation, Signaling, and Physiological Functions of G-Proteins. J. Mol. Biol. 428, 3850-3868.

Team, R.C. (2020). R: A language and environment for statistical computing. Version 4.0. 2 (Taking Off Again). R Foundation for Statistical Computing, Vienna, Austria.

Uhlén, M., Fagerberg, L., Hallström, B.M., Lindskog, C., Oksvold, P., Mardinoglu, A., Sivertsson, Å., Kampf, C., Sjöstedt, E., Asplund, A., et al. (2015). Proteomics. Tissue-based map of the human proteome. Science 347, 1260419.

UniProt Consortium (2021). UniProt: the universal protein knowledgebase in 2021. Nucleic Acids Res. 49, D480-D489.

Vass, M., Podlewska, S., de Esch, I.J.P., Bojarski, A.J., Leurs, R., Kooistra, A.J., and de Graaf, C. (2019). Aminergic GPCR-Ligand Interactions: A Chemical and Structural Map of Receptor Mutation Data. J. Med. Chem. 62, 3784-3839.

Versele, M., Lemaire, K., and Thevelein, J.M. (2001). Sex and sugar in yeast: two distinct GPCR systems. EMBO Rep. 2, 574-579.

Wickham, H., Averick, M., Bryan, J., Chang, W., McGowan, L., François, R., Grolemund, G., Hayes, A., Henry, L., Hester, J., et al. (2019). Welcome to the tidyverse. J. Open Source Softw. 4, 1686.

Wong, B.S., Manabe, N., and Camilleri, M. (2010). Role of prucalopride, a serotonin (5$\mathrm{HT}(4))$ receptor agonist, for the treatment of chronic constipation. Clin. Exp. Gastroenterol. 3, 49-56.

Yasi, E.A., Allen, A.A., Sugianto, W., and Peralta-Yahya, P. (2019). Identification of Three Antimicrobials Activating Serotonin Receptor 4 in Colon Cells. ACS Synth. Biol. 8, 27102717.

Zhang, D., Zhao, Q., and Wu, B. (2015). Structural Studies of G Protein-Coupled Receptors. Mol. Cells 38, 836-842.

GTEx Consortium. 2013. “The Genotype-Tissue Expression (GTEx) Project.” Nature Genetics 45 (6): 580-85. 
bioRxiv preprint doi: https://doi.org/10.1101/2021.07.12

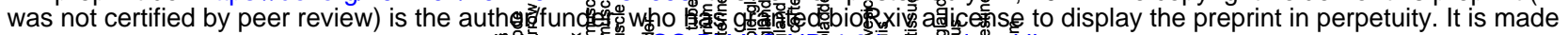
avaigate li

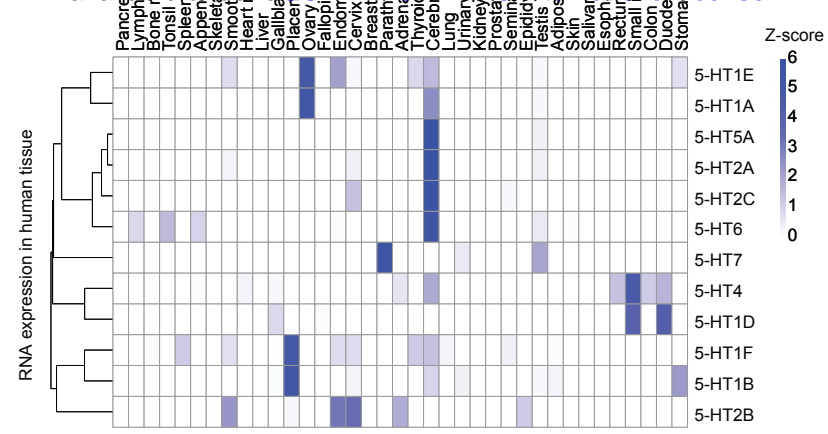

B

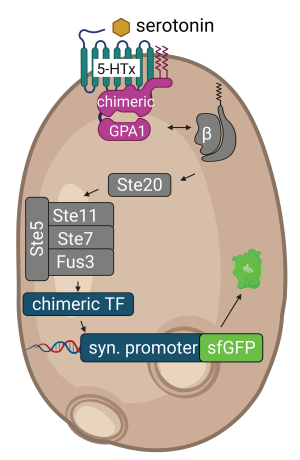

C

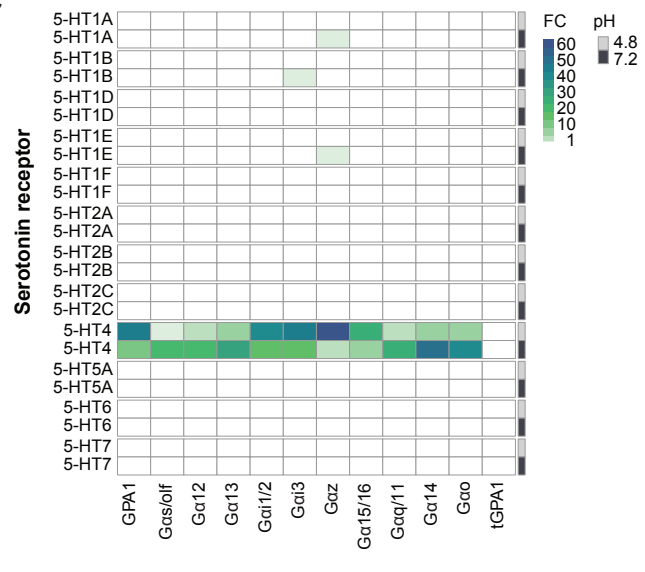

Ga background

Figure 1. 
bioRxiv preprint doi: https://doi.org/10.1101/2021.07.12.452006; this version posted July 12, 2021. The copyright holder for this preprint (which was not certified by peer review) is the author/funder, who has granted bioRxiv a license to display the preprint in perpetuity. It is made available under aCC-BY-NC-ND 4.0 International license.
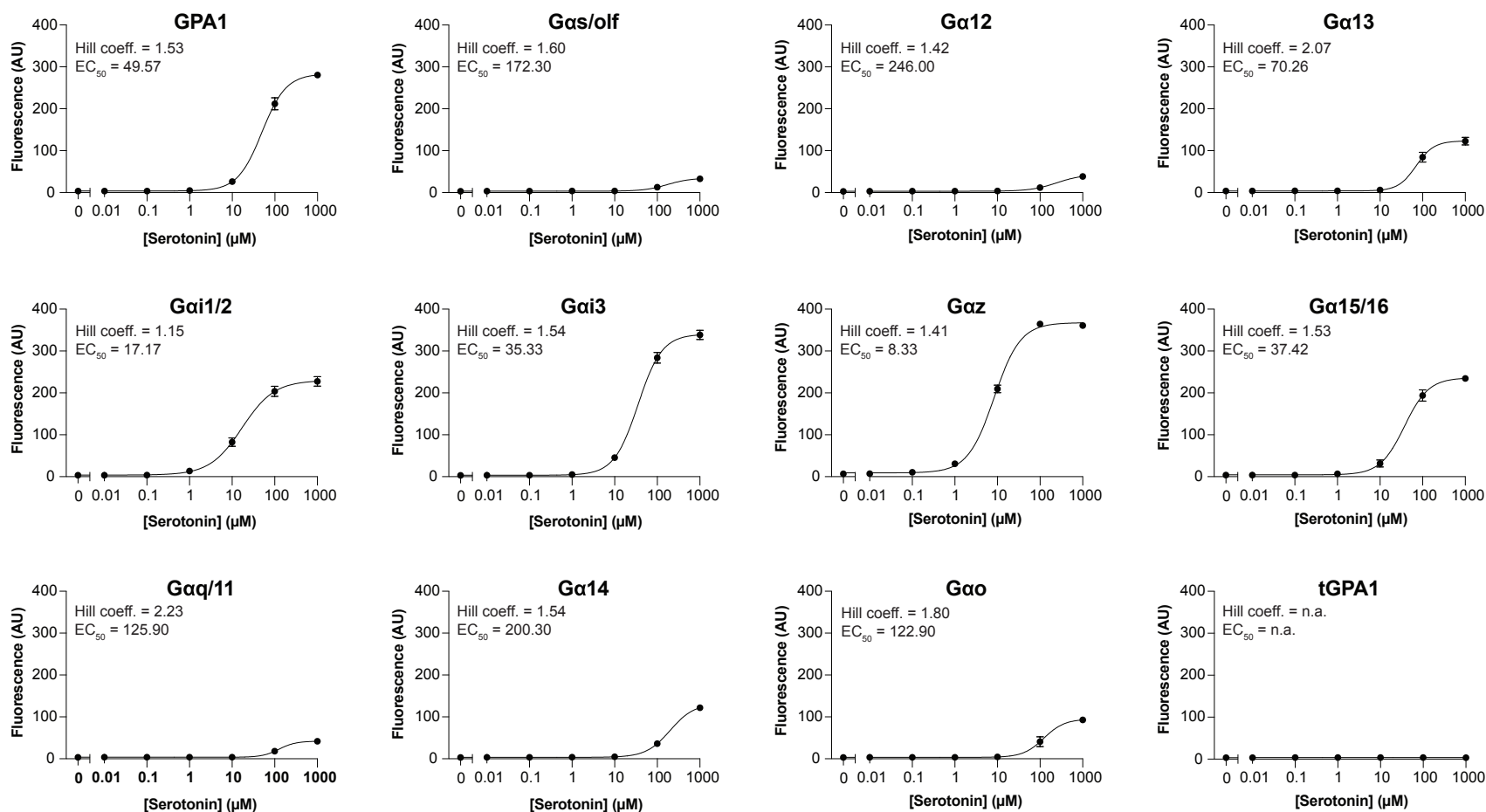

Figure 2. 


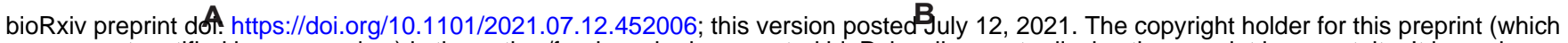
was not certified by peer review) is the author/funder, who has granted bioRxiv a license to display the preprint in perpetuity. It is made

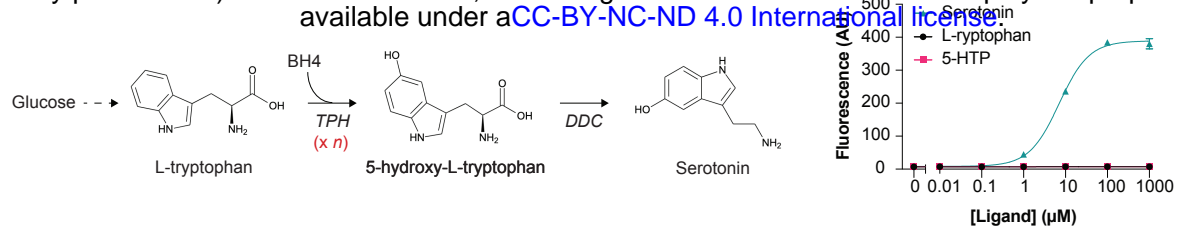

C
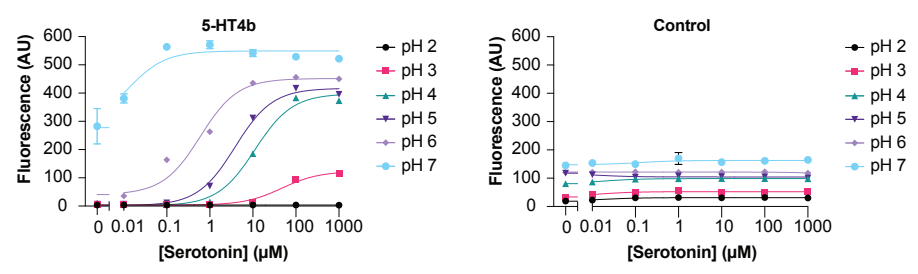

D

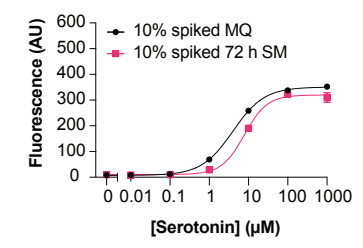

E

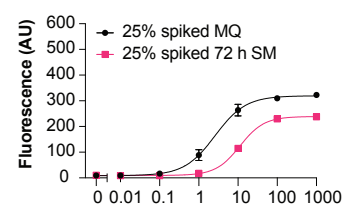

[Serotonin] $(\mu \mathrm{M})$

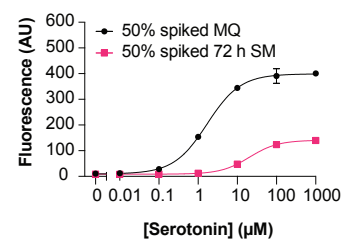

$\mathbf{F}$

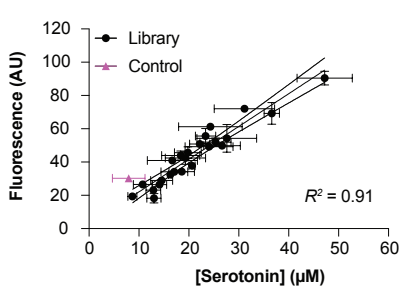

Figure 3. 
bioRxiv preprint doi: https://doi.org/10.1101/20.98 1.07.12.45\%806; this version posted July 12, 2021. The copyright holder for this preprint (which was not certified by peer review) is the author/funder, who gias granted bioRxiv a license to display the preprint in perpetuity. It is made

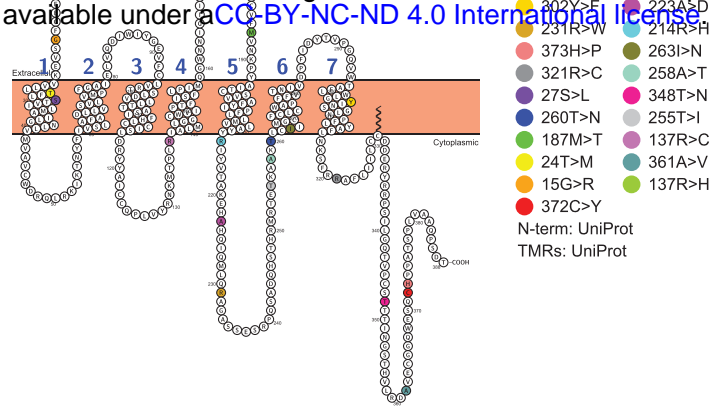

B
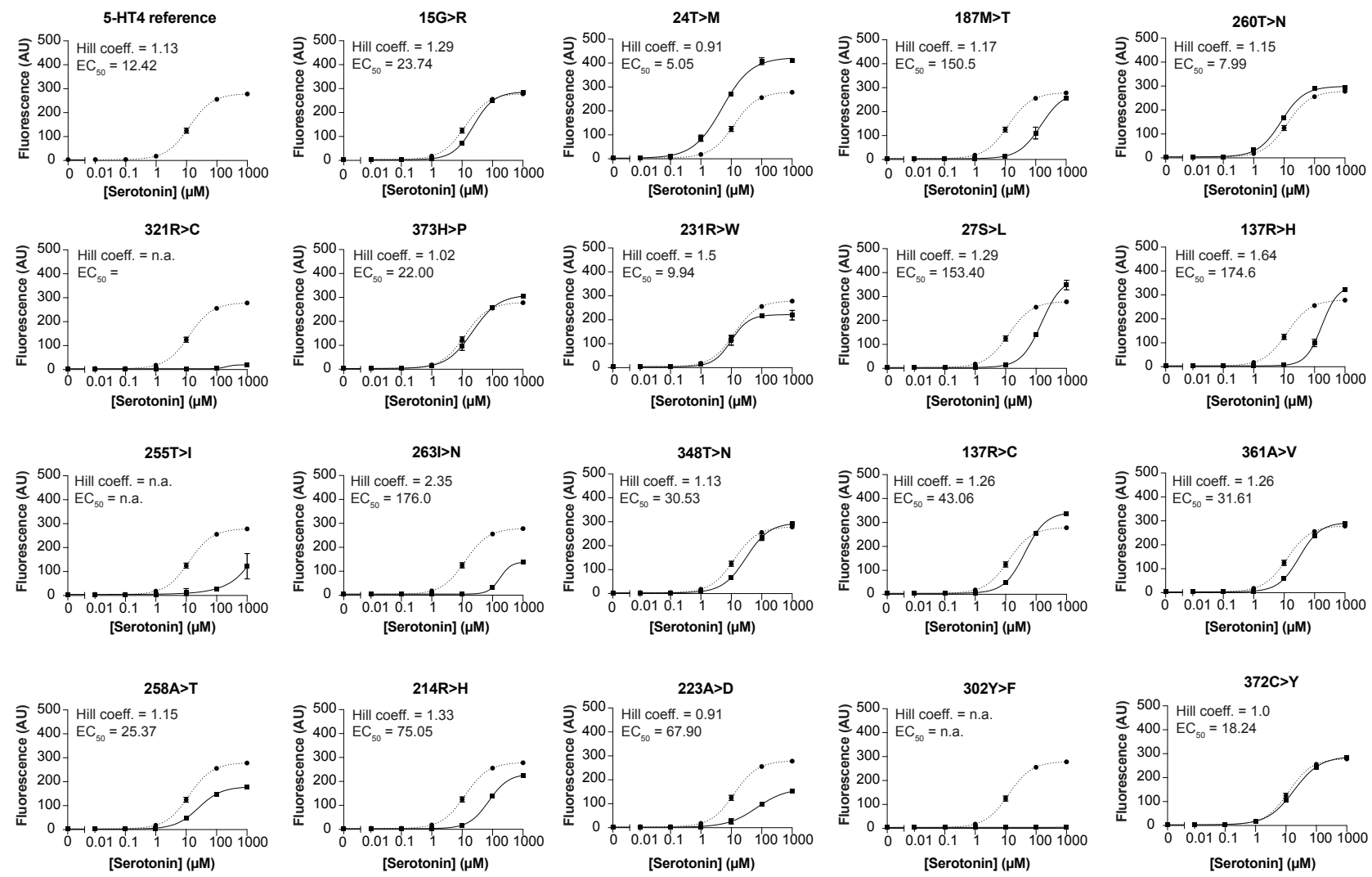

Figure 4. 